\title{
Uma Ferramenta de Telepresença Imersiva usando Oculus Rift
}

\author{
Philip K. Dunker, Alberto B. Raposo \\ Departamento de Informática, PUC-Rio \\ \{pdunker,abraposo\}@ tecgraf.puc-rio.br
}

\begin{abstract}
Telepresence refers to a set of technologies that allows a person to feel as if he is in a place other than his true location. This work presents a tool composed of a head-mounted display (HMD), the Oculus Rift DK1, integrated with a device called remote head, able to film with a stereo camera and to transmit to the Oculus Rift the images in 3D. At the same time, the HMD's gyroscope captures the user's head orientation and sends it to the remote head, which has servo motors able to rotate it in order to allow the user to move the stereo camera without any additional device. The project's goal is to provide the user an experience of immersive telepresence, with a low cost and a simple interface. Some tests with users were performed and indicated the benefit of some features of the tool, such as stereoscopic vision and the remote head rotation.
\end{abstract}

Resumo. Telepresença refere-se a um conjunto de tecnologias que permite uma pessoa se sentir como se estivesse presente em um lugar que não seja a sua verdadeira localização. Neste trabalho apresentamos uma ferramenta composta por um head-mounted display (HMD), o Oculus Rift DK1, integrado com um dispositivo nomeado de cabeça remota $(C R)$, capaz de filmar usando uma câmera estéreo e transmitir para o Oculus Rift as imagens em 3D. Ao mesmo tempo, o giroscópio do HMD captura a orientação da cabeça do usuário e envia para a cabeça remota, que possui servo motores capazes de girá-la a fim de possibilitar o usuário movimentar a câmera estéreo sem nenhum dispositivo adicional. $O$ objetivo é proporcionar uma experiência de telepresença imersiva, com uma interface de baixo custo e simples de usar. Foram realizados testes com usuários com cenários experimentais, que indicaram o benefício de alguns recursos da ferramenta, como a visão estereoscópica e a rotação da cabeça remota.

\section{Introdução}

Telepresença refere-se a um conjunto de tecnologias que permite uma pessoa se sentir como se estivesse presente em um lugar que não seja a sua verdadeira localização. Telepresença imersiva é o próximo passo e o objetivo passa por proporcionar a sensação de que o utilizador se encontra completamente imerso num ambiente remoto [Terrile \& Noraky, 2012]. Para que isso ocorra, os sentidos do usuário precisam ser estimulados e, quanto mais sentidos forem estimulados e quanto mais fortes forem esses estímulos, maior será a sensação de imersão [Rodrigues, 2015].

Este trabalho tem como objetivo criar uma ferramenta que dê ao usuário uma 
experiência de telepresença imersiva. Acreditamos que é possível atingir este objetivo com o uso de equipamentos de baixo custo existentes no mercado, capazes de capturar imagens de um ambiente em 3D, exibi-las para um usuário em 3D, ao mesmo tempo em que este usuário não precisa utilizar nenhum controle físico em suas mãos para manipular as câmeras, pois através de sensores é possível detectar a rotação da cabeça do usuário e girar a câmera da mesma forma. Isso é possível com o uso de um headmounted display (ou HMD) em conjunto com um dispositivo desenvolvido neste trabalho, chamado de cabeça remota (CR).

Um HMD, de uma maneira geral, é um equipamento de realidade virtual que exibe ao usuário as informações de um ambiente (geralmente virtual) em 3D. Os equipamentos mais modernos possuem um giroscópio capaz de detectar os movimentos de rotação da cabeça do usuário. A cabeça remota (CR) é um equipamento que utiliza dois sevo-motores, uma câmera estéreo e uma placa de prototipagem que possui um micro controlador, chip inteligente que consiste num circuito processador que possui entradas, saídas e uma memória, e comunica-se com um computador via porta USB.

Com esses dois componentes integrados é possível estimular o sentido da visão, o principal sentido para dar o sentimento de imersão ao usuário, com imagens de um ambiente real em 3D (capturadas pela câmera estéreo) e girar a câmera a partir das rotações capturadas pelo giroscópio, de forma natural para o usuário. Dessa forma, o usuário poderá ter um sentimento de presença imersiva no ambiente remoto real.

A ferramenta desenvolvida pode ser usada, por exemplo, em videoconferências, em novas formas de turismo onde o "viajante" pode ver pontos turísticos como se estivesse presente neles sem sair de casa, dentre outras possibilidades de uso. A ferramenta também poderá ser adaptada para ser usada em outras situações, como acoplada a qualquer robô que possua um operador que o controle de longa distância, como: drone, ROV (Remotely Operated Vehicle) ou UGV (Unmanned Ground Vehicle). No entanto, o presente projeto não foi desenvolvido para uma aplicação específica. $\mathrm{O}$ objetivo do trabalho foi o desenvolvimento de um sistema simples e barato, com o qual pudéssemos fazer avaliações sobre a importância dos recursos de estereoscopia e rotação da cabeça remota na telepresença imersiva.

Este artigo está organizado da seguinte forma: na Seção 2 são discutidos alguns conceitos e trabalhos relacionados. Na Seção 3, a solução proposta e os equipamentos são apresentados. Na Seção 4, é demonstrada a arquitetura do sistema e cada um dos componentes é descrito. Uma avaliação da ferramenta feita por usuários é apresentada na Seção 5. Por fim, a conclusão e discussão sobre possíveis trabalhos futuros encerram o artigo.

\section{Trabalhos Relacionados}

Existe certo desentendimento na literatura a respeito da definição precisa de telepresença e um dos motivos para isso é sua grande quantidade de denominações, que inclui: synthetic presence, virtual presence, social presence, ego presence $\mathrm{e}$ telepresence. Cada um desses termos refere-se a uma experiência que envolve dar a impressão ao usuário de que ele está em um ambiente remoto, virtual ou não, mediado por computador, por vezes em conjunto com outros equipamentos eletrônicos, e cada um dos termos é usado de forma idiossincrática dentro de seu contexto específico. 
Hendrix e Barfield observaram que virtual presence (sentir-se presente em um ambiente virtual) ou telepresence (sentir se presente em um ambiente remoto real) são fenômenos indistinguíveis psicologicamente. Portanto, parece ser apropriado fazer comparações baseadas apenas na experiência do usuário [Hendrix \& Barfield, 1996].

A ideia de telepresença surgiu pela primeira vez a partir de referências anedóticas para a sensação de ser deslocado de uma sala de controle local para uma área remota ao usar uma ferramenta de teleoperação [Minsky, 1980]. Mesmo antes, em 1971, discutia-se a importância da criação de controles "para ajudar o operador a projetar sua presença" em locais de trabalho remotos e fornecendo monitores que "melhoram a identificação do operador com a tarefa" [Johnsen \& Corliss, 1971]. A partir desses estudos percebeu-se que a melhor maneira de se criar uma ferramenta de teleoperação era proporcionando ao teleoperador a sensação mais próxima possível de estar em contato direto com o ambiente onde deve ser executada a tarefa.

A dificuldade em compreender o significado de telepresença parte da maneira relativamente descuidada com que o termo é usado. Draper [Draper, 1995] encontrou três definições de telepresença de uso comum: a simples, a cibernética e a experimental. $\mathrm{Na}$ definição da simples, telepresença refere-se à habilidade de operar em um ambiente mediado por computador. Por exemplo, Travis, Watson e Atyeo [Travis et al., 1994] escreveram que telepresença "implica em controlar máquinas (usualmente robôs) à distância”.

$\mathrm{Na}$ definição cibernética, telepresença é um índice da qualidade da interface humano-computador. Por exemplo, Thomas e Karl Smith [Smith \& Smith, 1990] argumentaram que telepresença ocorre quando "as características operacionais da interface humano-computador são compatíveis com as capacidades de desempenho comportamental-fisiológicas e as limitações do ser humano".

$\mathrm{Na}$ definição experimental, telepresença é um estado mental em que o usuário se sente fisicamente presente dentro do ambiente mediado por computador [Akin et al., 1983]. Por exemplo, Sheridan [Sheridan, 1992a] descreveu telepresença como uma "sensação de estar fisicamente presente com objetos virtuais no local remoto teleoperado". Sheridan [Sheridan, 1992b] novamente a descreveu em outro lugar como uma "ilusão" que ocorre quando o usuário "se sente fisicamente presente no local remoto".

A diferença fundamental entre a telepresença cibernética e experimental é que a definição cibernética se refere à eficiência de displays e controles, enquanto a definição experimental refere-se a algo experimentado pelo usuário humano. A característica diferencial da telepresença experimental é o estado mental, o que inclui a suspensão da consciência do usuário e o afastamento dele para o ambiente mediado por computador. A qualidade da interface humano-computador é frequentemente citada como um fator determinante da intensidade da experiência, mas telepresença experimental é claramente algo além da telepresença cibernética.

No presente trabalho, não entraremos mais a fundo na discussão sobre os diferentes tipos de telepresença. Usaremos a definição mais simples de telepresença de Hendrix e Barfield [Hendrix \& Barfield, 1996], mencionada anteriormente: sentir-se presente em um ambiente remoto real. Em particular, estamos interessados no conceito 
de telepresença imersiva, que significa prover ao usuário a habilidade de sentir-se presente e interagir com o ambiente remoto através de gestos e movimentos [Rodrigues, 2015].

A telerrobótica, área da robótica responsável pelo controle de robôs semiautônomos à distância, exige que algum tipo de telepresença seja criado, por isso a telepresença e a telerrobótica se misturam. Neste campo de pesquisa existem projetos que usam dispositivos HMDs para o usuário ter a sensação de presença e ser capaz de realizar alguma tarefa robótica com maior facilidade. Isso acontece, principalmente, porque existem ambientes que são inacessíveis para o homem ou porque colocaria a vida de uma ou mais pessoas em risco. Esses sistemas são usados em diversas situações: na exploração espacial como o robô "Robonaut" [Goza, 2004], para fins militares, como em missões de busca e salvamento [Elliott et al., 2012], entre outras situações.

Antes do ano de 2012, o acesso a dispositivos HMDs era mais difícil, já que eram dispositivos caros e com baixa qualidade visual. Em 2012, foi lançada a primeira versão, para desenvolvedores, dos Oculus Rift a um preço acessível e com uma qualidade visual satisfatória. Desde então muitos outros projetos usando esse equipamento começaram a surgir, porém, como ainda estão em fase de desenvolvimento, não há muita informação a respeito. Encontramos alguns projetos similares ao apresentado neste artigo basicamente em vídeos do YouTube ou em sites das instituições desenvolvedoras.

Em 2012, Linda Elliott descreveu experiências feitas com veículos terrestres não-tripulados, usados pelo exército americano em missões de busca e salvamento, onde operadores utilizaram um sistema com visão e áudio estereoscópico e 13 dos 18 operadores preferiram o sistema de telepresença imersivo em oposição aos utilizados hoje em dia com câmeras e monitores comuns [Elliott et al., 2012]. Isso indica o potencial benefício da telepresença imersiva também em operações militares.

A ideia de controlar drones em primeira pessoa também não é nova, existem os chamados drones FPV (first person view). Porém, eles possuem câmeras comuns. A Intuitive Aerial, uma empresa da Suécia especializada em drones, está desenvolvendo um projeto objetivando criar drones FPV com câmera estereoscópica (www.intuitiveaerial.com).

Da mesma forma, a manipulação remota de robôs também tem se utilizado de estereoscopia e HMDs. Por exemplo, há um projeto do Robotics Lab (http://robotics.cs.uml.edu) da Universidade de Massachusetts em que o objetivo é manipular um robô remotamente do ponto de vista do robô com visão 3D, e assim executar tarefas com precisão ${ }^{1}$.

O sistema desenvolvido no presente trabalho relaciona-se com os citados acima porque também tem o objetivo de dar a sensação ao usuário, com um HMD, de que ele se encontra em outro ambiente, onde está a cabeça remota, equipamento criado para gravar e enviar imagens em 3D e interagir girando a câmera. Porém, diferentemente da maioria dos trabalhos acima citados, não visamos inicialmente uma aplicação específica, mas sim o desenvolvimento de um sistema simples e barato que possa ser usado em

\footnotetext{
${ }^{1}$ www.youtube.com/watch?v=JHIz-Y5qCmY
} 
diferentes aplicações e, no caso específico deste artigo, queremos avaliar o efeito da visão estereoscópica e da rotação remota da cabeça em um cenário típico de videoconferência.

\section{Solução Proposta}

Para a criação de uma ferramenta de telepresença imersiva, a solução proposta é trazer para o ambiente real a imersão atingida pelos HMDs em ambientes virtuais. Estes equipamentos, além de permitirem a visualização de imagens em 3D, possuem sensores capazes de rastrear a posição e orientação da cabeça do usuário. De posse dessas informações, um software é capaz de transladar e rotacionar uma câmera virtual em um mundo virtual imitando os movimentos reais do usuário, consequentemente, este se sente mais imerso do que se a câmera estivesse parada ou se ele a movimentasse com controles comuns. Segundo Sutherland, a variação que ocorre na imagem quando o usuário move sua cabeça deve alternar exatamente do mesmo modo que a imagem de um verdadeiro objeto mudaria para movimentos semelhantes do usuário. Ela é mais importante para a imersão do que a própria apresentação estereoscópica [Sutherland, 1968].

Nossa solução propõe a criação de um equipamento, para ser utilizado juntamente com um HMD, capaz de filmar em 3D e girar esta câmera imitando os movimentos do usuário. A solução proposta é dividida em dois módulos:

- Módulo do operador: responsável por exibir para o operador em 3D imagens do ambiente remoto em tempo real, capturar movimentos de rotação da cabeça do operador e enviá-los para o módulo da cabeça remota.

- Módulo da cabeça remota: responsável pela captura de imagens em 3D e enviálas para o módulo do operador, ao mesmo tempo em que recebe rotações da cabeça do operador e gira a câmera estéreo com as rotações recebidas.

\subsection{Módulo do Operador}

O hardware do módulo do operador consiste basicamente no Oculus Rift DK 1, com resolução total da tela de 1280 x 800, mas como é dividida, então a resolução fica 640 x 800 por olho.

Os óculos têm incorporado três sensores que monitoram movimentos da cabeça do utilizador: magnetômetro, acelerômetro e giroscópio. A combinação desses sensores permite rastrear com precisão as rotações da cabeça do utilizador nos eixos X, Y e Z.

O software deste módulo precisa continuamente receber um par de imagens do módulo da cabeça remota, enviá-las para o Rift, ao mesmo em tempo que consulta a orientação dele e envia para a cabeça remota.

\subsection{Módulo da Cabeça Remota}

A cabeça remota $(\mathrm{CR})$ é o módulo mais complexo porque é a junção de três equipamentos eletrônicos. Ela possui os seguintes equipamentos: uma câmera: DUO MLX, da DUO 3D ${ }^{2}$; uma placa StartUSB for PIC, da MikroElektronika ${ }^{3}$; e dois mini

\footnotetext{
${ }^{2}$ www.duo3d.com
} 
servo motores ES9258, da EMAX . $^{4}$

A câmera DUO MLX é uma câmera binocular que permite filmar em estéreo e é bem compacta, de dimensões 52 x 25.4 x 13.3 milímetros e peso 12,5 gramas. Possui uma boa taxa de quadros por segundo (56 quadros por segundo na sua resolução máxima de 752x480). O único ponto negativo é que as imagens são monocromáticas.

A placa StartUSB for PIC é uma placa com componentes eletrônicos voltada para o desenvolvimento de sistemas embarcados. Ela possui um microcontrolador e os componentes eletrônicos necessários para a comunicação do microcontrolador com um computador via USB.

O servo motor é um dispositivo eletromecânico, que apresenta movimento proporcional a um comando. Sua característica principal é a capacidade de movimentar o seu braço até uma posição e mantê-lo, mesmo quando sofre uma força em outra direção. Em contraste com os motores contínuos que giram indefinidamente, o eixo dos servo motores possui uma faixa de rotação que varia de acordo com o modelo, mas são precisos quanto à sua posição. Foram utilizados dois servo motores do modelo ES9258 da EMAX, que embora tenham bom torque e velocidade para girar a câmera DUO MLX, têm uma faixa de rotação de apenas $60^{\circ}$.

Esses três equipamentos juntos formam a Cabeça Remota (CR) - Figura 1. Com apenas dois servo motores, optamos por girar a cabeça remota apenas nos eixos X e Y, excluindo o giro no eixo $\mathrm{Z}$ (movimento de roll, conforme detalhe na Figura 1). Foi necessário ainda usar uma fonte externa de $5 \mathrm{~V}$ que também foi usada de base para prender a placa e os motores. O suporte da câmera é bem simples: um dos motores segura a câmera e o outro motor segura a base do primeiro motor.

\section{Implementação}

Visando uma implementação modularizada capaz de manipular e testar cada equipamento eletrônico de forma independente, foram implementados cinco componentes. A Figura 2 mostra a integração dos componentes com os módulos.

- CameraDUODll - componente responsável pela comunicação com a câmera DUO MLX, armazenamento das imagens e disponibilização dessas imagens através de uma interface. Nessa DLL ficam todas as funções necessárias para manipular este hardware: a função de inicialização, de início de captura das imagens, de registro da função de call-back, de encerramento do uso do hardware, entre outras.

- Visualizador - componente que recebe as imagens e as reproduz no Oculus Rift. Este componente foi desenvolvido no Unity3D, ferramenta de desenvolvimento de jogos que possui integração com a biblioteca do Oculus Rift, a LibOVR.

- RiftSensor - componente responsável pela captura dos movimentos da cabeça do usuário, ou seja, monitora os sensores do Oculus Rift e é também responsável pelo envio das rotações para o componente CommWithPic.

\footnotetext{
${ }^{3}$ www.mikroe.com

4 www.emaxmodel.com
} 

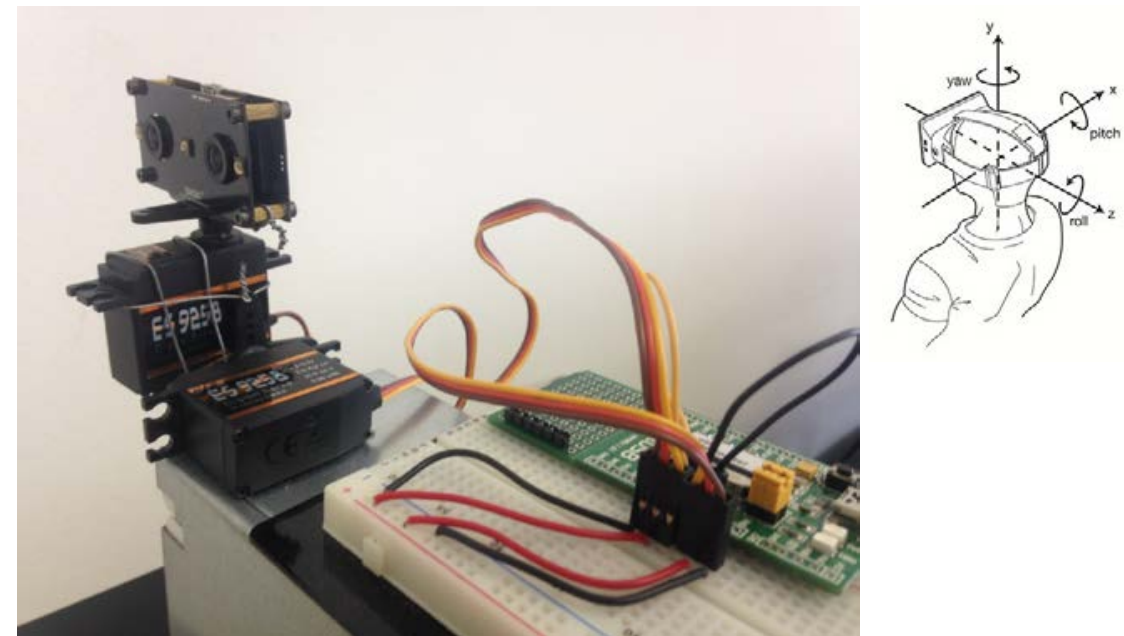

Figura 1. Cabeça remota e eixos de rotação da cabeça do usuário com o HMD.

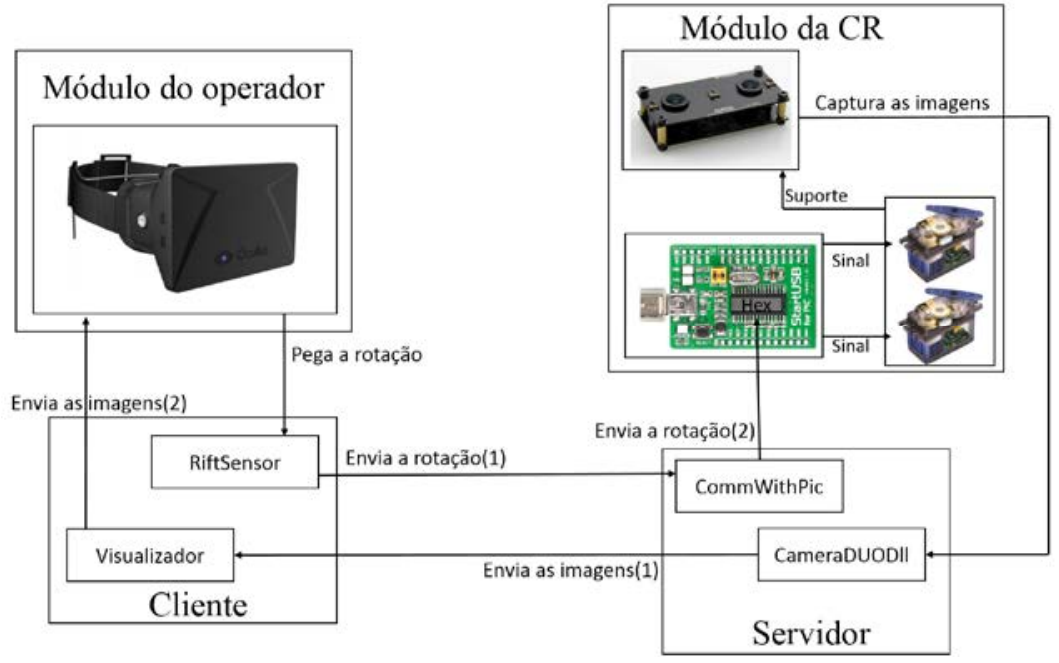

Figura 2. Diagrama dos módulos e componentes.

A comunicação com o microcontrolador é dividida em duas partes, o software executado em um computador e o programa gravado no microcontrolador:

- CommWithPic - componente responsável pelo recebimento e envio das rotações para o microcontrolador. Este componente foi escrito na linguagem C\#; ele recebe informações de quanto cada motor deve girar e em qual direção e repassa essas informações para o componente Hex (programa gravado no microcontrolador).

- Hex - componente responsável pelo recebimento das rotações e atuador nos servo motores (programa executado no microcontrolador).

Os componentes CameraDUODll, CommWithPic e Hex fazem parte do servidor e o cliente é composto pelos componentes Visualizador e Rift Sensor. Dessa forma o servidor provê as imagens do ambiente remoto para o cliente.

Duas implementações distribuídas foram testadas: a primeira implementação utilizava os mecanismos do Unity3D e a segunda implementação utilizava a API de 
sockets do Windows (Windows Sockets API - WSA). No entanto, nenhuma dessas implementações resultou em um tempo de latência satisfatório para uma atividade em tempo real. Por isso, implementamos o sistema localmente para realização dos testes com usuários. Para que o operador com o Oculus Rift e a Cabeça Remota ficassem em ambientes diferentes foram usados dois cabos extensores do tipo USB e HDMI de 10 metros, que são os cabos necessários para o funcionamento do Oculus Rift, conforme é mostrado na próxima seção.

\section{Avaliação com Usuários}

A avaliação foi feita baseando-se nas respostas dos usuários por meio da aplicação de dois questionários após a utilização da ferramenta em um cenário mimetizando uma videoconferência que englobava um teste de estereoscopia. Esse experimento teve como objetivo avaliar a sensação de presença dos usuários no ambiente remoto, bem como se a ferramenta de telepresenca imersiva traz benefícios ao utilizador quando se trata de videoconferências.

\subsection{Cenário de Teste}

Doze usuários foram convidados a participar do projeto, voluntariamente, após assinatura do Termo de Consentimento Livre e Esclarecido. O cenário de teste foi composto pelo participante em um ambiente com o HMD enquanto o avaliador encontrava-se em outra sala diante da cabeça remota (CR) e com o modelo físico (MF) usado no teste de estereoscopia (Figura 3).

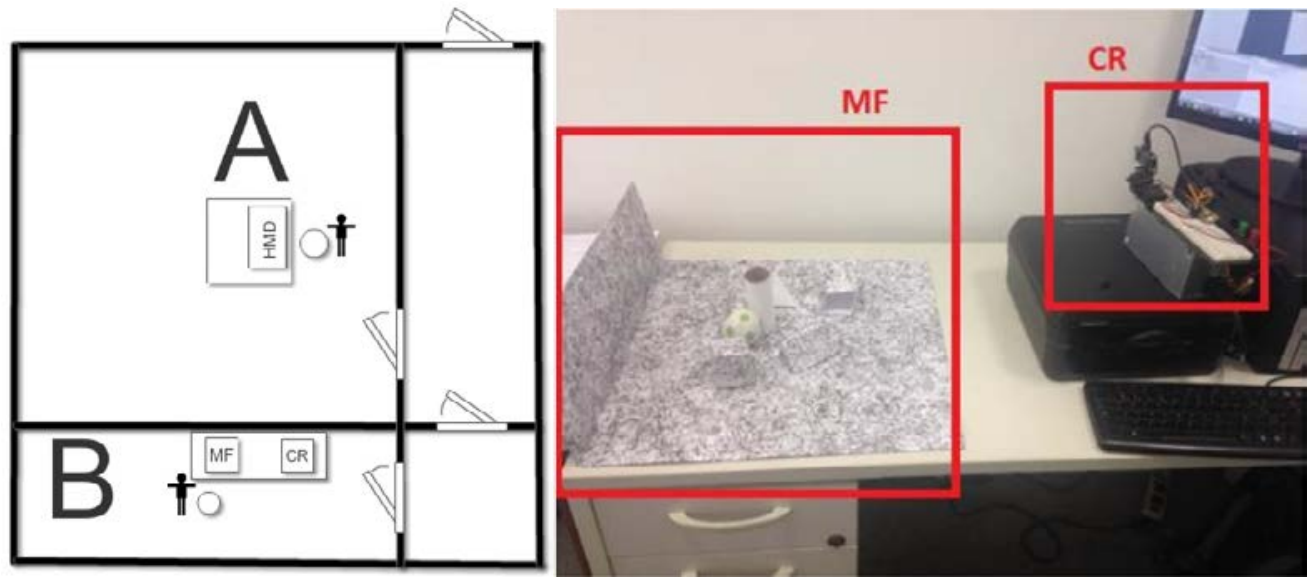

Figura 3. À esquerda: cenário de teste; A: ambiente dos participantes; B: ambiente do avaliador. À direita: cabeça remota (CR) e modelo físico (MF) no ambiente do avaliador.

Para que o ambiente de uma videoconferência fosse inteiramente recriado (com imagem e som) foi necessária a utilização de um sistema para transmissão de áudio, como Skype, ligação via WhatsApp ou ligação telefônica. Dessa forma, foi possível que o usuário interagisse com o avaliador.

O modelo físico utilizado consiste em uma maquete com seis formas geométricas, três delas brancas e três com a mesma textura do fundo (Figura 3). O teste de estereoscopia, por sua vez, apresentou três layouts distintos do modelo físico ao participante que diferiam nas posições dessas formas geométricas. O teste também 
contou com três modos de utilização da cabeça remota:

- Com visão estereoscópica e sem rotação das câmeras (3D sRot);

- Sem visão estereoscópica e com rotação das câmeras (2D cRot);

- Com visão estereoscópica e com rotação das câmeras (3D cRot).

A Tabela 1 mostra como ficou definido o modo de utilização da cabeça remota em cada um dos layouts para cada participante.

Tabela 1. Ordem de execução dos testes para cada participante.

\begin{tabular}{|c|l|}
\hline Número do participante & Ordem dos layouts (modo da CR) \\
\hline $1,4,7,10$ & A (3D sRot), B (2D cRot), C (3D cRot) \\
\hline $2,5,8,11$ & A (3D cRot), B (3D sRot), C (2D cRot) \\
\hline $3,6,9,12$ & A (2D cRot), B (3D cRot), C (3D sRot) \\
\hline
\end{tabular}

Inicialmente, um tempo do teste foi dispensado para o usuário acomodar-se com o equipamento. Em seguida, o avaliador exibiu um dos layouts com um dos modos de operação da cabeça remota acima citados, iniciando o teste de estereoscopia. O usuário foi questionado em relação à quantidade de formas geométricas e a posição ocupada por elas na maquete, avaliado assim a profundidade dos objetos (do mais perto para o mais longe) enquanto o avaliador anotava as respostas. Este procedimento foi repetido até que os três modos fossem experimentados pelo usuário. Por fim, o usuário respondeu a dois questionários, conforme será descrito a seguir.

\subsection{Metodologia de Avaliação}

O uso de questionários, uma forma bastante utilizada para medição de presença, permite adquirir dados a respeito da experiência do usuário, tendo em vista que é composto por um conjunto de perguntas direcionadas. Além disso, possui baixo custo, fácil aplicabilidade e não interrompe a experiência do usuário, pois permite a análise e interpretação dos dados em um segundo momento pelo avaliador. Uma desvantagem é qu,e por serem aplicados posteriormente, dependem da capacidade de memorização dos participantes, que está sujeita ao esquecimento de detalhes vivenciados no momento da experiência.

Um primeiro questionário experimental (Tabela 2) foi desenvolvido especificamente para este cenário de teste. Ele é composto por perguntas que visam obter as impressões do usuário ao utilizar o equipamento e avalia questões subjetivas que variam de acordo com cada participante. Conforto, facilidade de manuseio, sincronia entre rotação da câmera e do HMD e a melhora comparativa entre a visão monocular e binocular foram os parâmetros avaliados por este questionário.

O questionário "Igroup Presence Questionnaire" (IPQ) foi o meio utilizado para mensurar o sentimento de presença do usuário no ambiente remoto. Em sua origem, ele foi idealizado para avaliar o senso de presença do usuário em um ambiente virtual. Neste trabalho, o IPQ foi adaptado para avaliar o senso de presença no cenário relatado acima, um ambiente remoto real. Os termos que faziam referências ao ambiente virtual 
("virtual") foram substituídos por referências ao ambiente remoto ("remote").

Tabela 2. Questionário experimental.

\begin{tabular}{|l|}
\hline \multicolumn{1}{|c|}{ Questionário Experimental } \\
\hline Perguntas Iniciais \\
\hline Você está se sentindo confortável com o HMD? \\
\hline Você consegue movimentar a câmera da CR com facilidade? \\
\hline Você consegue perceber algum atraso da imagem comparado ao som? \\
\hline Perguntas sobre MF (feito 3 vezes, alternado layouts e modos de operação da CR) \\
\hline Quantos objetos geométricos você vê nesse modelo? \\
\hline Diga a ordem desses objetos de mais perto para mais longe: \\
\hline Perguntas finais \\
\hline $\begin{array}{l}\text { Qual a sua impressão com relação a controlar a câmera a partir dos movimentos da } \\
\text { sua cabeça? }\end{array}$ \\
\hline $\begin{array}{l}\text { A velocidade do giro da câmera acompanha a velocidade de movimentação da sua } \\
\text { cabeça? }\end{array}$ \\
\hline $\begin{array}{l}\text { Após mudar da visão mono para a visão estereoscópica, o que você acha da sua noção } \\
\text { de profundidade? }\end{array}$ \\
\hline $\begin{array}{l}\text { Em algum momento da experiência você se sentiu mal? (desorientação, tontura, } \\
\text { enjoo, vista cansada ou náusea) }\end{array}$ \\
\hline
\end{tabular}

O IPQ foi criado por um grupo de pesquisadores, o Igroup Project Consortium (www.igroup.org/projects/ipq/), com base em questionários anteriores. Numa primeira fase 240 participantes responderam um grande número de itens em uma pesquisa online. Estes dados foram analisados por métodos estatísticos e reaplicados em uma segunda fase de pesquisa on-line com mais de 200 participantes. Como resultado, 14 itens foram selecionados para compor o IPQ através de uma escala de sete pontos ( -3 a +3), aplicada de forma rápida e simples. Destes, um item tem uma abordagem genérica avaliando a "sensação de estar lá" enquanto os outros 13 medem três fatores (Figura 4): presença espacial, envolvimento e realismo experimentado.

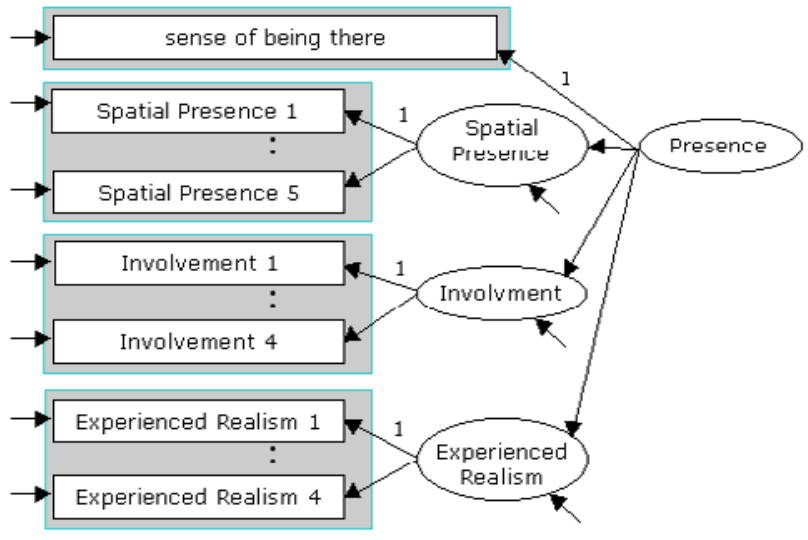

Figura 4. Fatores do IPQ (http://www.igroup.org/pq/ipq/construction.php).

Dos 14 itens do IPQ, os últimos 4 (11-14) foram excluídos dos nossos testes porque fazem referência ao realismo experimentado e, por se tratar de ambiente remoto real, a avaliação do realismo não seria coerente.

Devido a sua grande utilização em diversos estudos, este questionário também permite a comparação dos resultados obtidos com os dados coletados por outros pesquisadores, reunidos em um banco de dados. 


\subsection{Resultado dos Testes}

Os 12 participantes dos testes tinham média de idade de 28,5 anos com desvio padrão de 2.5 anos, a maioria (10 deles) do sexo masculino, havendo prevalência na área de exatas. Destes, $75 \%$ não possuíam problema de vista e não utilizavam óculos ou lentes de contato. Três participantes não tinham experiência prévia com um HMD.

A análise das respostas da primeira parte do Questionário Experimental, realizada oralmente pelo avaliador durante o período de acomodação do usuário, permitiu inferir que todos os participantes sentiram-se confortáveis ao utilizar o equipamento, sendo que $25 \%$ deles classificaram a experiência como muito confortável, $50 \%$ como confortável e $25 \%$ como normal. Além disso, todos os participantes conseguiram movimentar facilmente a câmera da $\mathrm{CR}$ e não perceberam nenhuma latência na transmissão do som em relação à imagem.

A segunda parte do Questionário Experimental questionava sobre a quantidade e a ordem dos objetos presentes no modelo físico. A quantidade era avaliada através da percepção do usuário do número de objetos presentes em seu campo visual, incluindo objetos camuflados com o objetivo de dificultar a visualização dos mesmos. A ordem dos objetos avaliava a noção de profundidade do usuário que deveria informar ao avaliador a sequência dos objetos de mais perto para mais longe.

A Figura 5 representa, de forma genérica, os acertos e os erros obtidos em cada modo de operação. No modo 2D com rotação houve um índice de acerto de $25 \%$ (3 usuários). Já no modo 3D sem rotação, aproximadamente, 33,3\% dos usuários obtiveram êxito em suas respostas. O maior índice de acertos foi constatado no modo 3D com rotação. Neste, $75 \%$ dos participantes responderam corretamente.

\section{ACERTOS X ERROS NOS DIFERENTES MODOS DE OPERAÇÃO}

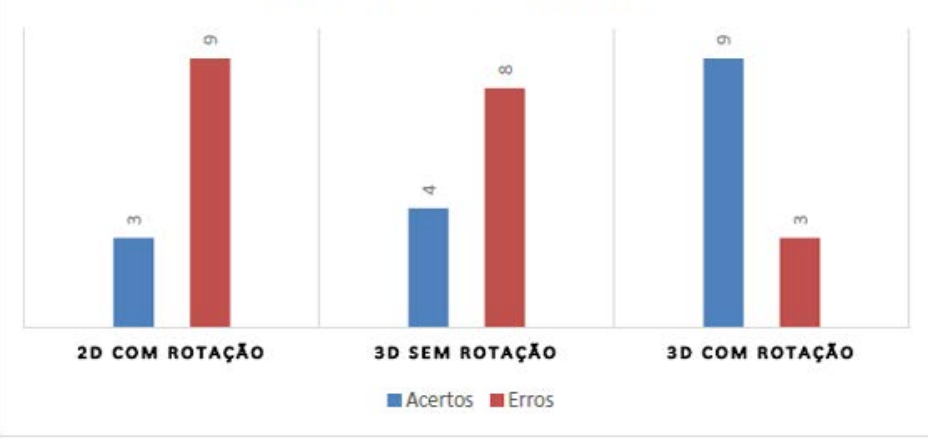

Figura 5. Erros vs. acertos.

A Figura 6 classifica os tipos de erros obtidos, subdividindo-os em erros na ordem dos objetos, erros na quantidade ou em ambos. Dos nove participantes que não responderam corretamente no modo $2 \mathrm{D}$ com rotação, três erraram a ordem, quatro não visualizaram algum objeto e dois erraram ambos os quesitos. Já no modo 3D sem rotação, dois erraram na ordem, cinco não visualizaram algum objeto e um errou ambos os quesitos. No modo 3D com rotação, que obteve o menor índice de erros, dois usuários erraram a ordem e um o número de objetos. Neste modo nenhum participante errou os dois quesitos. A partir desses dados podemos perceber que o modo 3D sem 
rotação diminuiu o erro na ordem, mas aumentou o erro na não visualização de objetos (quantidade). Isso mostra que o 3D ajuda a compreender a profundidade dos objetos e a rotação da câmera ajuda a visualizar os objetos camuflados, que têm textura igual à do fundo. Portanto, o modo 3D com rotação, por ser uma combinação dos dois fatores, mostrou-se superior aos demais.

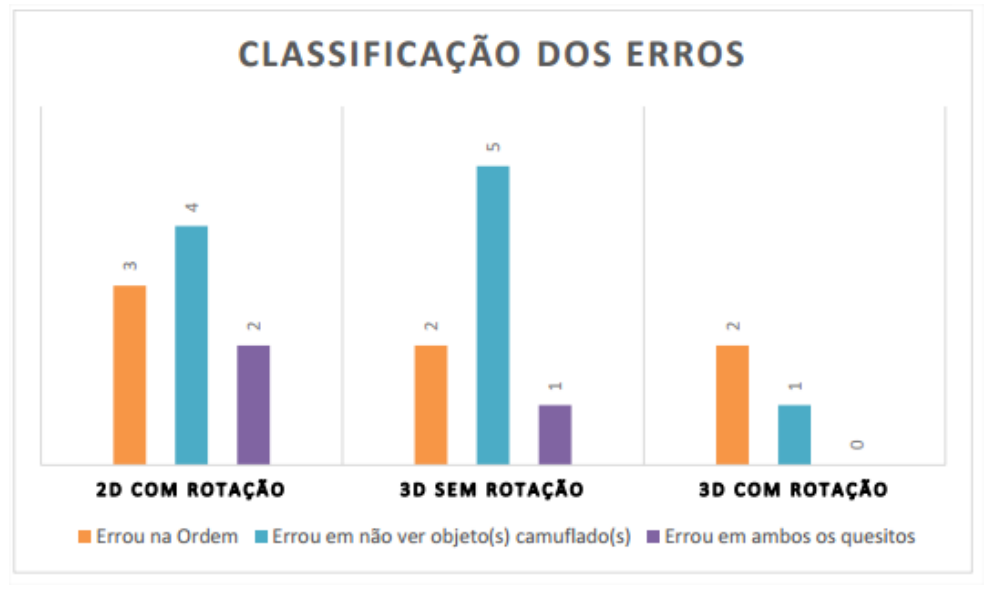

Figura 6. Classificação dos erros.

Após vivenciar os três modos de operação, o usuário encerrou sua experiência com o sistema e foi submetido à terceira parte do Questionário Experimental, em que suas impressões seriam avaliadas. $O$ controle da câmera a partir dos movimentos do usuário foi considerado bastante natural por $42 \%$ dos participantes. Este controle foi julgado bom por $50 \%$ e médio por $8 \%$. A velocidade do giro da câmera acompanhou a velocidade de movimentação do usuário em 75\% dos casos (acompanha $=58 \%$; acompanha muito bem $=17 \%$ ). Para $25 \%$ dos participantes ocorre um atraso entre essas velocidades.

A mudança da visão mono para a estereoscópica foi representativa para todos os usuários. A noção de profundidade melhorou muito em $67 \%$ dos casos e para $33 \%$ a melhora não foi tão expressiva. Por fim, o usuário foi questionado se em algum momento da experiência sentiu algum tipo de desconforto, tais como: desorientação, tontura, náusea ou vista cansada. Nenhuma dessas sensações ocorreu em $75 \%$ dos usuários.

A última etapa do teste com usuários foi o preenchimento do IPQ. Apesar da escala do questionário ter uma faixa de -3 a +3 , para fins de análise e estatísticas, os valores são transformados para uma nova faixa de 0 a 6 , sendo 0 a pior e 6 a melhor pontuação com exceção dos itens SP2 e INV3 que possuem uma escala invertida. A Tabela 3 mostra a média e o desvio padrão das respostas dos usuários, com os itens SP2 e INV3 já corrigidos.

O item G1 é quesito genérico. Ele sozinho compõe o fator que avalia a sensação de estar no ambiente remoto $(\mathrm{G})$. A média dos itens SP1 ao SP5, que compõem o fator de presença espacial (SP), resultou em 4,17, enquanto a média dos itens INV1 ao INV4, o fator envolvimento (INV), resultou no valor de 3,96 (Figura 7). 
Tabela 3. Média e desvio padrão das respostas ao IPQ ( $R E$ significa "remote environment").

\begin{tabular}{|c|l|c|c|}
\hline IPQ item & \multicolumn{1}{|c|}{ "Atalho" } & Média & Desvio Padrão \\
\hline G1 & sense of being there & 4,25 & 0,83 \\
\hline SP1 & sense of surrounded by $R E$ & 4,17 & 0,69 \\
\hline SP2 & felt like just perceiving pictures & 4,67 & 1,31 \\
\hline SP3 & sense of not being in $R E$ & 5,58 & 1,61 \\
\hline SP4 & sense of acting in $R E$ & 4,08 & 1,38 \\
\hline SP5 & sense of being present in $R E$ & 4,33 & 1,34 \\
\hline INV1 & awareness of my real (local) env & 3,83 & 1,46 \\
\hline INV2 & not aware of my real environment & 4,17 & 1,85 \\
\hline INV3 & attention to my real environment & 3,92 & 1,11 \\
\hline INV4 & attention captivated by RE & 3,92 & 1,34 \\
\hline
\end{tabular}

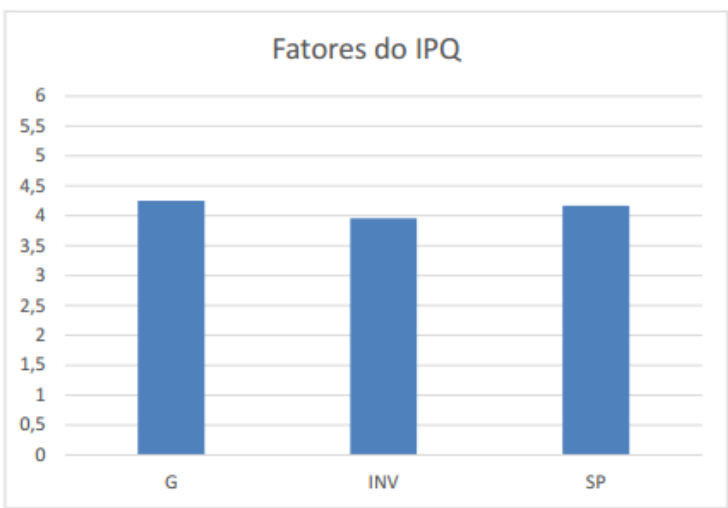

Figura 7. Resultados obtidos nos fatores do IPQ.

Como dito anteriormente, o IPQ permite a análise comparativa entre diversos trabalhos que usaram este questionário. $\mathrm{O} \mathrm{PQII}^{5}$, estudo realizado pelo Igroup, avaliou os jogos Half-Life e Tomb Raider. Além disso, também foi feita uma comparação entre a média dos 542 dados que compõem o banco de informações do IPQ. A Figura 8 mostra a comparação entre os perfis de presença desses estudos e o obtido no presente trabalho. O perfil de presença do sistema desenvolvido foi superior aos demais em todas as variáveis. Por se tratar de um ambiente remoto real, vale lembrar que o fator realismo foi excluído. Cabe ressaltar, no entanto, que essa comparação é apenas ilustrativa, pois foram experimentos realizados por grupos diferentes, com números de usuários diferentes, com equipamentos e propósitos diferentes. O dado mais relevante é verificar que o sentimento de presença do dispositivo desenvolvido ficou acima da média do banco de informações do IPQ (em preto na Figura 8).

\footnotetext{
${ }^{5}$ http://www.igroup.org/pq/ipq/data.php
} 


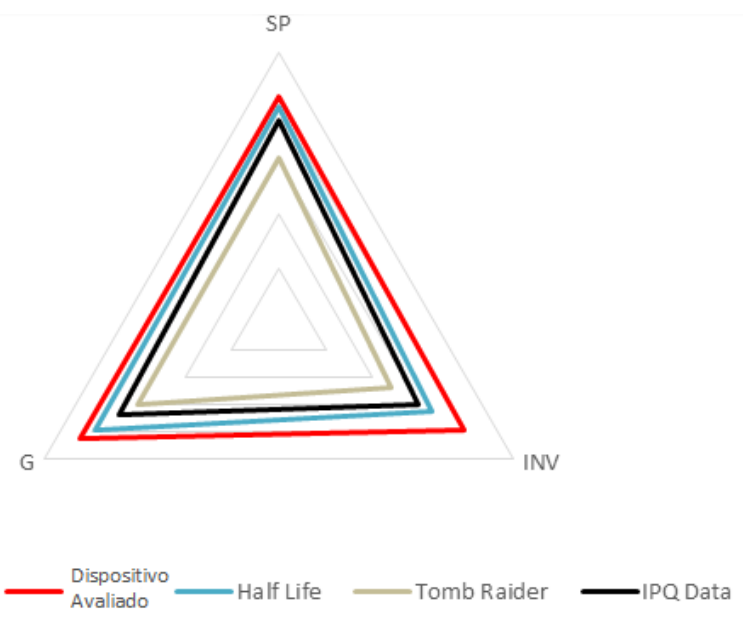

Figura 8. Comparação dos resultados do IPQ com outros trabalhos.

\section{Conclusão}

Neste trabalho foi proposta e avaliada uma ferramenta de telepresença imersiva. Apesar de algumas limitações no hardware, como a câmera monocromática, faixa de rotação dos servo motores de $60^{\circ}$ e ausência de um terceiro servo motor para rotação no eixo $\mathrm{Z}$, o protótipo desenvolvido conseguiu proporcionar ao usuário uma experiência de telepresença imersiva e avaliar a impressão durante seu uso.

A análise dos testes permitiu inferir que o dispositivo consegue reproduzir o ambiente de uma videoconferência e possibilita uma melhora em relação aos dispositivos comuns. Isso ocorre devido à visualização do ambiente em $3 \mathrm{D}$ e pela manipulação da câmera através do HMD, sem a necessidade de controles adicionais. Os resultados demonstraram que a ferramenta desenvolvida permite uma boa sensação imersiva. O uso da visão estéreo foi considerado um grande avanço na visualização do ambiente remoto em relação à visão mono, tendo em vista o maior número de acertos nos testes e da percepção, inclusive, de objetos camuflados.

Um dado obtido que pode ter gerado dúvidas foi o fato de durante a primeira fase do questionário experimental todos os participantes terem classificado a experiência como confortável e em um momento posterior, $25 \%$ terem experimentado alguma sensação de desconforto. Isso pode ser explicado pela primeira fase do questionário ter sido realizada no momento inicial dos testes, enquanto o usuário experimentava a ferramenta. $\mathrm{O}$ desconforto, provavelmente, foi devido ao maior tempo de exposição ao dispositivo. Além disso, alguns participantes mencionaram trepidações durante a movimentação da cabeça remota, o que também pode contribuir para o mal-estar. Essas trepidações podem ter sido causadas pelo suporte de fio de ferro criado para acoplar os motores entre si e à câmera (Figura 1). Esse suporte pode ser melhorado utilizando engrenagens e roldanas que levariam a uma junção mais coesa, evitando a trepidação.

Em face dos dados apresentados o sistema desenvolvido cumpriu as expectativas. Porém, mudanças podem aperfeiçoar o protótipo, bem como destiná-lo a outros fins. As principais melhorias seriam a utilização de hardwares mais modernos como uma câmera estéreo colorida, servo motores de rotação contínua que permitem a rotação em $360^{\circ}$ e a utilização de mais um servo motor para possibilitar a rotação da 
câmera nos 3 eixos de rotação. Mudanças na implementação do software para um sistema distribuído também são essenciais para a utilização do sistema em longa distância. A utilização do protocolo UDP para envio das imagens seria uma alternativa para o desenvolvimento de um sistema distribuído com pouca latência.

\section{Referências}

Akin, D. L. et al. (1983). "Space Applications of Automation, Robotics and Machine Intelligence Systems (ARAMIS), phase 2". Volume 1: Telepresence technology base development.

Draper, John V. (1995). "Teleoperators for advanced manufacturing: Applications and human factors challenges". International Journal of Human Factors in Manufacturing, 5, 1: 53-85.

Elliott, Linda R. et al. (2012). "Robotic telepresence: Perception, performance, and user experience”. Technical Report No. ARL-TR-5928. Army Research Lab Aberdeen Proving Ground MD Human Research and Engineering Directorate.

Goza, S. M. et al. (2004). "Telepresence control of the NASA/DARPA robonaut on a mobility platform". In: Proceedings of the SIGCHI conference on Human factors in computing systems. ACM, 623-629.

Hendrix, C.; Barfield, W. (1996). "Presence within virtual environments as a function of visual display parameters". Presence: Teleoperators \& Virtual Environments, 5, 3: 274-289.

Johnsen, Edwin G.; Corliss, William R. (1971). "Human factors applications in teleoperator design and operation". New York: Wiley-Interscience.

Minsky, M. (1980). Telepresence. Omni, p. 45-51.

Rodrigues, F. A. C. (2015). "Immersive Telerobotic Modular Framework using stereoscopic HMDs". 110 f. Dissertação (Mestrado Integrado em Engenharia Informática e Computação) - Faculdade de Engenharia, Universidade do Porto.

Sheridan, Thomas B. (1992a). "Musings on telepresence and virtual presence". Presence: Teleoperators \& Virtual Environments, 1,1: 120-126.

Sheridan, Thomas B. (1992b). Telerobotics, automation, and human supervisory control. MIT press.

Smith, T. J.; Smith, K. U. (1990). "The human factors of workstation telepresence". In: NASA, Lyndon B. Johnson Space Center, Third Annual Workshop on Space Operations Automation and Robotics (SOAR 1989), 235-250.

Sutherland, I. E. (1968). "A head-mounted three dimensional display." In: Proceedings of the December 9-11, 1968, fall joint computer conference, part I. ACM.

Terrile, Richard J., Noraky, James. (2012) "Immersive telepresence as an alternative for human exploration". Aerospace Conference, IEEE.

Travis, David; Watson, Toby; Atyeo Mike (1994). "Human psychology in virtual environments". Interacting with virtual environments: 43-59. 